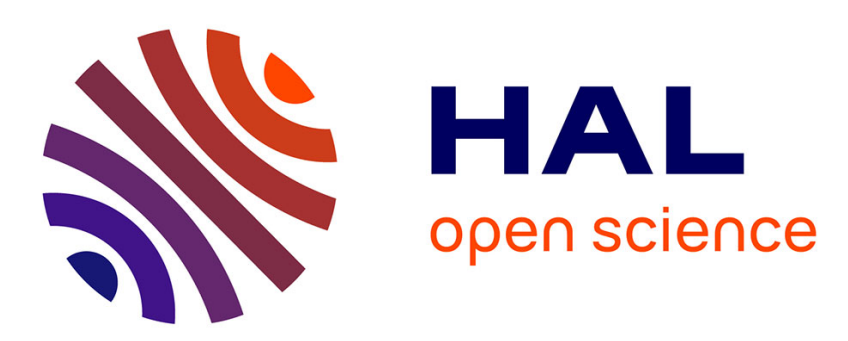

\title{
Environmental assessment of trout farming in France by life cycle assessment: using bootstrapped principal component nalysis to better define system classification
}

Xiaobo Chen, Elisabeth Samson, Aurélien Tocqueville, Joël Aubin

\section{- To cite this version:}

Xiaobo Chen, Elisabeth Samson, Aurélien Tocqueville, Joël Aubin. Environmental assessment of trout farming in France by life cycle assessment: using bootstrapped principal component nalysis to better define system classification. Journal of Cleaner Production, 2015, 87, pp.87-95. 10.1016/j.jclepro.2014.09.021 . hal-01209001

\section{HAL Id: hal-01209001 https://hal.science/hal-01209001}

Submitted on 27 May 2020

HAL is a multi-disciplinary open access archive for the deposit and dissemination of scientific research documents, whether they are published or not. The documents may come from teaching and research institutions in France or abroad, or from public or private research centers.
L'archive ouverte pluridisciplinaire HAL, est destinée au dépôt et à la diffusion de documents scientifiques de niveau recherche, publiés ou non, émanant des établissements d'enseignement et de recherche français ou étrangers, des laboratoires publics ou privés. 


\title{
Environmental assessment of trout farming in France by life cycle assessment: using bootstrapped principal component analysis to better define system classification
}

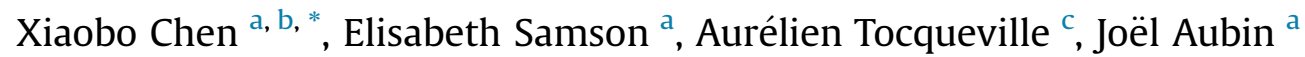 \\ a INRA, UMR 1069 Sol, Agro et hydrosystème Spatialisation, F-35042 Rennes, France \\ ${ }^{\mathrm{b}}$ Agrocampus Ouest, F-35042 Rennes, France \\ c ITAVI, F-75009 Paris, France
}

\section{A R T I C L E I N F O}

\section{Article history:}

Received 21 February 2014

Received in revised form 19 August 2014

Accepted 4 September 2014

Available online 16 September 2014

\section{Keywords:}

Life cycle assessment

Non-parametric bootstrap

Principal component analysis

Trout farming system

\begin{abstract}
A B S T R A C T
Trout farming is the main fish production system in France. This article describes a system to classify trout farms based on environmental impacts calculated by life cycle assessment and technical and economic indicators. Since the number of surveyed farms was too small for a robust assessment, we combined principal component analysis (PCA) with a non-parametric bootstrap technique. French trout farms were surveyed to collect technical and economic indicators. The representativeness of the survey was verified by comparing it to a national inventory. Life cycle assessment was used to estimate environmental impacts of farms and the contribution of each production stage to impacts. PCA was used to evaluate both technical-economic and environmental indicators of the trout farms, which were separated into three groups based on the size of fish produced (pan-size, large and mixed-size, and very large). Non-parametric bootstrap was used to compare the groups and to test the significance of PCA results. Results validated the fish-farm classification system based on the size of fish produced and indicated that farm operations and fish feeding contributed the most to environmental impacts. The PCA method distinguished three groups via their technical indicators, with non-significant differences among the groups in environmental impacts. However, environmental indicators showed strong links with technical and economic indicators. In conclusion, bootstrapped PCA offers the ability to assess groups of trout production system when the sample size is too small and provides more conservative results by considering uncertainty. Future studies should focus on providing reliable data to reduce uncertainty.
\end{abstract}

\section{Introduction}

Trout farming is the main aquaculture production system in France. It is primarily based on farming rainbow trout (Oncorhynchus mykiss) in flow-through systems, in which inlet water is diverted from a river, passed once through the rearing tanks and then returned to the river. All nutrients are provided by exogenous formulated feed containing fish meal, fish oil and plant-based ingredients. Production is carried out in small (10 t/year) to large farms (900 $t / y e a r)$. The farms have different production objectives responding to different markets. For example, some farms produce pan-sized trout or large trout for filets; other farms produce fish for restocking rivers or ponds for angling. These different production

\footnotetext{
* Corresponding author. INRA, UMR 1069 Sol, Agro et hydrosystème Spatialisation, F-35042 Rennes, France.

E-mail addresses: xiaobo.chen@rennes.inra.fr, xiaoboish@gmail.com (X. Chen).
}

strategies imply different practices (e.g., feed type, feeding management, oxygen supply, rearing densities, and water treatment). The trout farms in France are spread widely throughout the country, but their number is small (around 600) comparing to livestock systems. Since trout farming uses water of good quality, farm practices and the quality of water at their outlets are watched closely.

Despite the rapid growth of fish farming throughout the world (mean increase of fish production volume of $12 \%$ year in the last ten years) (FAO, 2012), trout production decreased in France from $47000 \mathrm{t}$ in 1997 to $37000 \mathrm{t}$ in 2007 (Agreste, 2011). This production suffers from economic competition from other aquatic products and the application of water-quality regulations (e.g., European Union Water Framework Directive), which can cause farmers to abandon fish production. The decrease in the number of farms and the corresponding decline in production led the French aquaculture producer organization (CIPA) to assess the sustainability of French 
trout farming. To do so, different approaches were applied: development of indicators of economic, social and environmental sustainability; environmental assessment of farms based on biological and chemical-physical measurements (Aubin et al., 2011); and life cycle assessment (LCA). This paper focuses on the definition of a trout-farm classification system using LCA indicators and certain technical and economic indicators.

LCA is a holistic method designed to estimate potential impacts associated with a product or service based on the resources consumed and pollutants emitted into the environment at all stages of its life cycle, from raw material extraction to its end-of-life (Guinée et al., 2002). It is an internationally accepted method described in ISO standards (ISO 14040 (2006), ISO 14044 (2006)). LCA has been adapted to fish farming (Papatryphon et al., 2004b) and applied in several studies to estimate environmental impacts of aquaculture in different contexts (Aubin, 2013; Cao et al., 2013; Henriksson et al., 2012). Salmonid production has been studied in particular, since it is common in Europe and North America. Moreover, it is a simple and well-controlled rearing system which fits with the industrial ecology rationale of LCA. Some studies about salmon production have investigated different rearing and feeding practices (Ayer and Tyedmers, 2009; Pelletier and Tyedmers, 2007; Pelletier et al., 2009). Other studies have investigated trout production (Aubin et al., 2009; Gronroos et al., 2006; Papatryphon et al., 2004b; Samuel-Fitwi et al., 2013). All of these studies helped to understand the contribution of system components to environmental impacts and showed the overwhelming influence of feed composition and management. Nevertheless, these studies were based on small numbers of farms.

To better understand the influence of rearing practices in trout farming, Papatryphon et al. (2004b) classified production systems into three classes according to the size of fish produced (pan-size, large trout, and very large trout). They observed high variability in the impact categories (relative variation ranged from $41 \%$ in biotic resource use to $87 \%$ in energy demand). Moreover, variability in impacts was associated with different production techniques; for example, variation in eutrophication was related mainly to differing feed efficiency among farms. However, the small number of farms investigated $(n=8)$ did not allow broader conclusions. As mentioned by Henriksson et al. (2012), the number of farms investigated often raises the question about the representativeness of aquaculture systems in LCA. As a consequence, environmental assessment of fish farms is relatively weak, making extrapolation of their potential environmental impacts delicate. To better characterize heterogeneous populations, especially in agricultural and aquacultural production, building classification systems is a common practice (Lazard et al., 2010). These classification systems are often based on surveys and statistical analysis, such as Principal Component Analysis (PCA).

PCA reduces the dimensionality of an observed dataset with many correlated variables by transforming them into a new set of variables, named principal components (PCs), which retain as much as possible the variation of the observed dataset (Jolliffe, 2005). It is used to extract the most important information from the dataset to get an overview of it in a small number of dimensions (e.g., two or three) described by their eigenvalues (measures of variation in samples explained by the PCs), loadings (coordinates of original variables in the PCs) and scores (coordinates of individuals in the PCs). PCA is commonly used to represent the variability in observed samples. However, a small sample size $(n<30)$ may not allow conclusions to be extrapolated to the entire population when the standard error of the mean is large (Berthouex and Brown, 2002). Hence, the consideration of uncertainty in the results due to small sample size is an important subject in statistical analysis. Indeed, this type of uncertainty can be expressed with a confidence interval (CI) or standard error (Luo et al., 2013; Melia et al., 2012).
Bootstrap sampling is a numerical method used to quantify uncertainty due to random sampling errors without assumptions about a variable's distribution (Efron, 1979). A bootstrapped sample is created by randomly sampling from an observed sample repeatedly. Bootstrap sampling can be applied, for example, to estimate the accuracy and stability of PCA results by providing a $\mathrm{CI}$ for eigenvalues and loadings (Babamoradi et al., 2013; Daudin et al., 1988; Timmerman et al., 2007). However, there are two shortcomings when using bootstrap-based PCA. First, the coordinates of component loadings and scores are arbitrary (Jackson, 1995; Jolliffe, 2005; Mehlman et al., 1995), which may overestimate the CI of loadings (reflection). Second, PCs may have a similar eigenvalues in a bootstrapped sample, which may change the order of PCs compared to the observed sample (re-ordering) (Timmerman et al., 2007). To address these problems, reflection and re-ordering corrections are performed on each bootstrapped sample (more details in Peres-Neto et al. (2003) and Babamoradi et al. (2013)).

In this study, we decided to bypass the problem of the small sample size of trout farms by using non-parametric bootstrap. This method has the advantage of being more robust than parametric bootstrap when the distribution of observed data fails a normality test. Therefore, to better understand the characteristics of French trout farms, this study used PCA to validate a classification system of French trout farms based on their types of commercial products. This system classifies trout farms based on their estimated environmental impacts and production techniques. The accuracy of PCA results $(\mathrm{CI})$ is evaluated with the bootstrap method.

\section{Materials and methods}

\subsection{Sample survey and national inventory}

A sample of 24 trout farms throughout France was selected based on the size of fish produced, hydrogeological characteristics of the environment, and farmer agreements. The farms were surveyed from 2007 to 2011, recording data such as farm production (types and quantities of products), farm inputs (types, quantities and origins, especially of energy sources, feed, juveniles, and water), infrastructure and equipment, and water quality (Aubin et al., 2011). Annual trout production of the farms varied from 20 to $667 \mathrm{t}$. Farms were divided into three groups according to the size of fish produced, as performed by Papatryphon et al. (2004b): G1, pan-size trout (250-400 g); G2, large and mixed-size trout (e.g., different sizes from 200 to $3000 \mathrm{~g}$ ); and G3, very large trout (>2000 g). The number of farms per group was 5, 9 and 10, respectively. To check the representativeness of the trout farm sample in the survey, we compared it to a classification of trout farms (defined by the amount of feed consumed) available in a 2007 inventory of French trout farms (Agreste, 2009).

\subsection{Life cycle assessment}

LCA was conducted according to the four steps and general requirements of the methodology proposed by ILCD (European Commission, 2010). The methodology was adapted to characteristics of fish farming. The goal and scope of this study is the environmental assessment of trout farming in France at the farm scale in order to adapt improvement strategies as a function of farm type. The boundary of the production system mainly contains farm operations, feed production (including ingredient production and transportation), production of juveniles, infrastructure construction, equipment manufacturing, and production of medicines and other inputs, such as liquid oxygen and energy carriers (Fig. 1). Despite the existence of thousands of processes in LCA of trout production, these processes are the most important contributors to overall impacts, according to the literature (Aubin, 2013). 
The life cycle was defined up to the farm gate, and the functional unit (impact calculation basis) was one $t$ of raw fish. Emissions of farm metabolic wastes (i.e., nitrogen and phosphorus compounds, suspended solids) into the aquatic environment were calculated using the mass-balance approach described by Papatryphon et al. (2005) and adapted by Aubin et al. (2011) to take into account internal dynamics of waste inside the farm. Specific information about feed ingredients came from Boissy et al. (2011). Economic allocation was used to divide environmental burdens among coproducts in feed-ingredient production. Secondary data (e.g., transport and electricity use) were extracted from the ecoinvent $v$. 2.2 database. LCA impact categories were selected to address a variety of environmental issues of fish farming. Climate change ( $\mathrm{kg}$ $\mathrm{CO}_{2}$-eq.), acidification ( $\mathrm{kg} \mathrm{SO}$-eq.), eutrophication ( $\mathrm{kg} \mathrm{PO}$-eq.) were calculated using the characterization factors of CML2 baseline 2000 v. 2.03 (Guinée et al., 2002). To consider the contribution of fish farming to land use, we selected a land occupation $\left(\mathrm{m}^{2 *} \mathrm{y}\right)$ indicator. Energy use of fish farming (energy demand (GJ)) was calculated according to the Cumulative Energy Demand method, v. 1.03 (Frischknecht et al., 2005). Water requirements of the activity (water dependence $\left(\mathrm{m}^{3}\right)$ ), including water consumption and water passing through the fish farm, was calculated according to Aubin et al. (2009). Net Primary Production Use (NPPU) (t C), which indicates the pressure of fish farming on biotic resources (especially marine resources), was calculated according to Papatryphon et al. (2004b). These LCA impact categories were selected based on previous studies and guidelines in the field of aquaculture LCAs (Aubin, 2013; Aubin et al., 2009; Henriksson et al., 2012; Pelletier and Tyedmers, 2007). The calculation of LCA impact categories was performed with SimaPro v. 7. Other indicators of rearing performances were added to reflect technical and economic characteristics of the systems: annual production level $(t)$, feed conversion ratio (FCR) and annual liquid oxygen consumption $(t)$. In addition, on-farm human labor (human.day) was included to highlight the relationship between production factors and labor on trout farms.

\subsection{Comparing differences in group means with the bootstrap method}

To identify significant differences among the three groups, we used the bias-corrected and accelerated (BCa) bootstrap method (see appendix) to calculate $95 \%$ CIs around the differences in group means, because it adjusts both bias and skewness in the bootstrap distribution and provides a reasonably accurate CI. Significant differences were assumed at $p<0.05$. The re-sampling procedure was performed 1000 times $(B=1000)$ using $\mathrm{R}(\mathrm{R}$ Development Core Team, 2012). Thus, we assumed that each group was independent and taken randomly from its own population. The differences

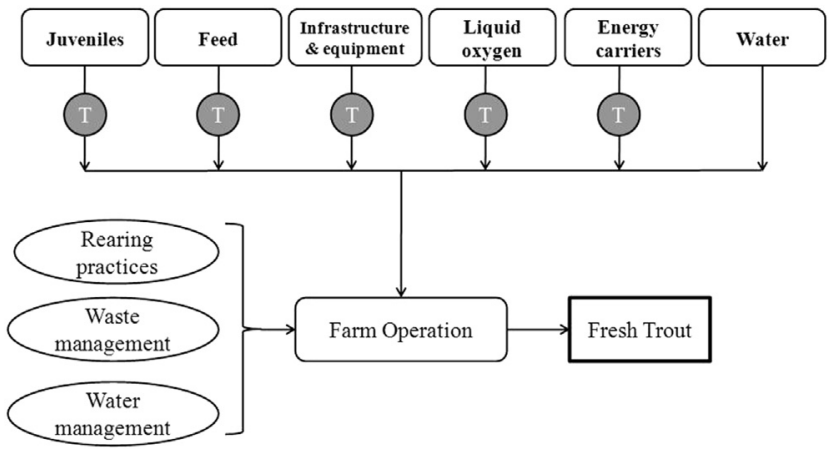

Fig. 1. System boundary of trout farming in France. Rounded rectangles represent processes of the production system. Ellipses represent management factors of fish farms. "T" means transportation. between groups were considered significant if the bootstrapped 95\% CIs around the differences included zero. In other words, the null hypothesis $\left(\mathrm{H}_{0}\right)$ was that differences between group means equaled zero. We chose a non-parametric bootstrap method to test differences between indicator means, because some of them (e.g., production level, liquid oxygen consumption, and acidification) might not satisfy normality or homogeneity of variance, two conditions required for parametric tests such as analysis of variance (ANOVA).

\subsection{PCA method}

To address the comparison problem due to the small sample size, we applied PCA ( $\mathrm{R}$ "princomp" function) to a matrix of eleven independent variables $(n=11)$ from observed samples $(m=24)$ and bootstrapped samples $\left(m^{*}=24\right)$ (Fig. 2). Through PCA, three vectors were generated: eigenvalues, loadings and scores. The $\mathrm{BCa}$ method was used to estimate $95 \%$ CIs for the eigenvalues of PCs to determine how many PCs to keep (bootstrapped Kaiser-Guttman criterion (Lambert et al., 1990)). So, only the components whose 95\% CI for the eigenvalues exceeded 1 (mean of eigenvalues) were retained. The loadings of original variables and the scores of individuals from the observed sample were mapped. We also used bootstrapped PCA $(B=1000)$ with re-ordering and reflection corrections to generate the component loadings and scores (PeresNeto et al., 2003). The significance of correlations between variables was tested by calculating BCa $95 \%$ CIs for correlation coefficients. The significance of variable loadings was tested by calculating $p$-values. They were calculated as the number of bootstrapped loadings smaller (when the original loadings were positive) or greater (when the original loadings were negative) than zero, divided by $B$ (Peres-Neto et al., 2003). Thus, variables were associated with the corresponding components when $p<0.05$. The individual scores of the three farm groups were distinguished by confidence regions ( $\mathrm{R}$ "ellipse" package) of the centroids of bootstrapped scores at a 90\% confidence level (Dehlholm et al., 2012).

\section{Results}

\subsection{Farm sample representativeness}

The observed sample included trout farms from all classes in the inventory except farms consuming less than $25 \mathrm{t}$ of feeds per year

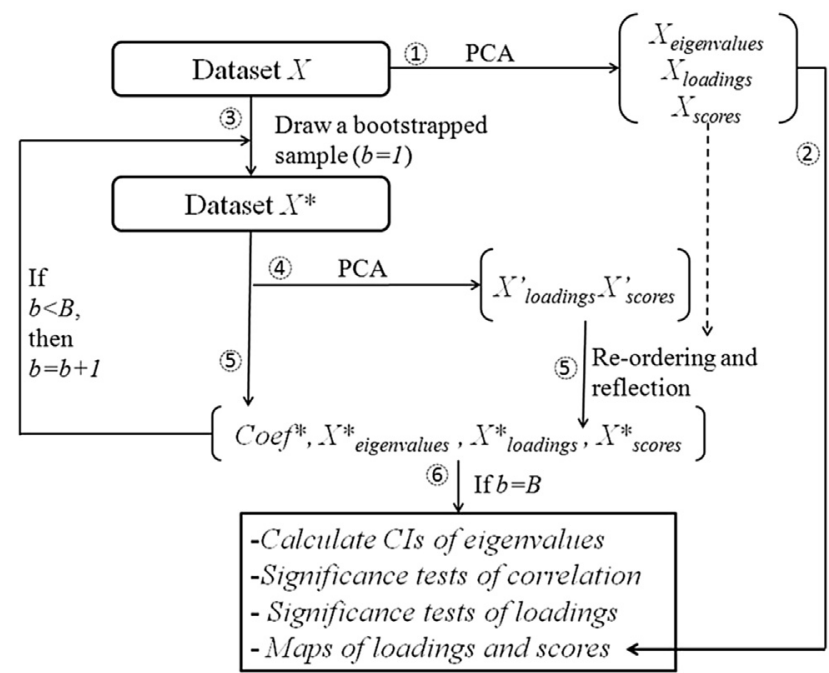

Fig. 2. Bootstrapped Principal Component Analysis (PCA) procedures with re-ordering and reflection corrections. 
(Table 1). Since this class represents only $6 \%$ of national feed consumption, it was not taken into account in our sample. The representativeness of the survey (expressed as the percentage of total national feed consumption) increased with the class size. The highest representativeness (40\%) was for farms consuming more than $500 \mathrm{t}$ of feed per year, while the lowest representativeness (5\%) was for farms consuming 25-50 t/year. The larger farms (feed consumption more than $300 \mathrm{t} / \mathrm{yr}$ ) are specialized in large trout production. Some of smaller farms (feed consumption less than 300 $\mathrm{t} / \mathrm{yr}$ ) are specialized in pan-size trout, while the others produced a combination of all sizes.

\subsection{Contribution analysis}

Among trout-production stages, feed (i.e., feed production, milling, and transport) was the main contributor to mean impacts, such as NPPU ( $\approx 94 \%$ ), land occupation (>92\%), climate change (67-73\%), acidification (63-69\%) and energy demand (50-59\%) (Fig. 3). Farm running (i.e., farm operations and on-farm emissions) was the main contributor to eutrophication (81-82\%) and water dependence (89-93\%) and influenced energy demand (20-26\%). Fry (i.e., production and transport of trout eggs or juveniles) contributed to acidification, eutrophication, climate change, energy demand and water dependence at a level of $7-14 \%$. It had a slight contribution (1-6\%) to NPPU and land occupation. The infrastructure and equipment (i.e., infrastructure, tank and building construction, equipment manufacturing and transport) only contributed to acidification, climate change and energy demand and their contributions were greatly variable among farm groups (2-16\%), with the highest levels always observed in group G2. Liquid oxygen (i.e., liquid oxygen production and transport) had higher contribution to acidification, climate change and energy demand (7-10\%) in groups G1 and G3 than in group G2. Chemicals (i.e., production and transport of medicines, cleaning products and other chemicals) had negligible contribution $(<1 \%)$. Except for land occupation and energy demand, all impacts decreased in this order: G2, G1, G3.

\subsection{Environmental impacts and rearing performance of the three groups}

Means and coefficients of variation (CV) of indicator values were calculated per group in the observed sample (Table 2). G1 had lower variability in acidification (12\%), eutrophication (6\%) and climate change (6\%) than G2 and G3 (>20\%). G2 had higher variability in most indicators than the other two groups, except for FCR and land occupation. Variability in liquid oxygen consumption was much higher in G2 (260\%) than in the other two groups (76\% and $67 \%$, respectively).
There were no significant differences in environmental impacts (e.g., acidification, eutrophication and climate change) or resource use (e.g., land occupation, energy demand and water dependence) between groups when comparing them with those of the bootstrap-based method (Fig. 3). However, there were significant differences in technical parameters between the groups, such as production level, feed consumption, liquid oxygen consumption, NPPU, water dependence and human labor. Although production level was significantly higher in G3 (440 t) than in G2 (79 t) and G1 $(168 \mathrm{t})$, FCR was not significantly different among the three groups. In addition, G2 had significantly higher NPPU and water dependence than G3, while no significant difference was found between G1 and the other two groups. For human labor, G2 required significantly more working time than the other two groups.

\section{4. $P C A$ results}

The eigenvalues of the first three PCs in the bootstrapped PCA were 3.8, 2.6 and 1.8, respectively. Since the lower limits of $95 \% \mathrm{CIs}$ calculated with the BCa method were less than 1, the first three PCs were selected, which explained a mean of $75 \%$ of the total variation in the observed sample, with a $95 \% \mathrm{CI}$ of $71-82 \%$. Significance tests of loadings indicated that acidification, eutrophication, climate change and energy demand were associated with the first PC (PC1); production level, liquid oxygen consumption, NPPU and human labor were associated with the second PC (PC2); and only FCR was associated with the third PC (PC3) (Table 3).

Acidification, eutrophication, climate change and energy demand had strong and significantly positive correlations $(r>0.5$, $p<0.05$ ) with each other, while NPPU, water dependency and human labor had significant negative correlations with production level and liquid oxygen consumption (Table 4). Eutrophication and climate change were significantly and negatively correlated with production ( -0.416 and -0.362 , respectively). In addition, FCR had strong significant correlations with land occupation $(r=0.610)$ and NPPU $(r=0.405)$. Also, NPPU was significantly correlated with human labor $(r=0.526)$, but not with water dependence.

The sample-based variable loadings and individual scores of PC1 versus PC2 were mapped (Fig. 4). Considering the confidence regions around centroids of each group, farms of G2 and G3 had a wider distribution on the map and were distinguished by technical and economic indicators, while those of G1 and G2 overlapped, which indicates similar characteristics. Some farms had extreme values, such as farms 4 and 10 in G3, which contributed strongly to PC1 and had high production but low environmental impacts. Farms 9 (G3) and 13 (G2) contributed strongly to PC2 but had different properties: the former consumed much more liquid oxygen, while the latter required more working time. Also, farm 18 in G2 had the highest environmental impacts.

Table 1

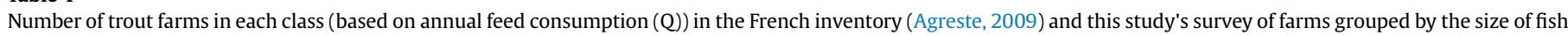
produced (G1: pan-size fish, G2: large and mixed-size fish, G3: very large fish).

\begin{tabular}{|c|c|c|c|c|c|c|c|c|}
\hline \multirow[t]{2}{*}{ Class } & \multicolumn{2}{|l|}{ National inventory } & \multicolumn{6}{|l|}{ Trout survey } \\
\hline & Number of farms & Total feed cons. (t/yr) & Number of farms & Total feed cons. (t/yr) & $\begin{array}{l}\text { Percentage } \\
\text { of national total (\%) }\end{array}$ & G1 (\%) & G2 (\%) & G3 (\%) \\
\hline$Q<25 \mathrm{t}$ & 366 & 2627 & 0 & 0 & 0 & 0 & 0 & 0 \\
\hline $25 \mathrm{t} \leq \mathrm{Q}<50 \mathrm{t}$ & 59 & 2174 & 3 & 99 & 5 & 0 & 100 & 0 \\
\hline $50 \mathrm{t} \leq Q<100 \mathrm{t}$ & 56 & 4143 & 4 & 239 & 6 & 27 & 73 & 0 \\
\hline $100 \mathrm{t} \leq Q<200 \mathrm{t}$ & 56 & 7908 & 5 & 697 & 9 & 38 & 36 & 26 \\
\hline $200 \mathrm{t} \leq \mathrm{Q}<300 \mathrm{t}$ & 27 & 6819 & 3 & 769 & 11 & 34 & 35 & 31 \\
\hline $300 \mathrm{t} \leq Q<500 \mathrm{t}$ & 25 & 9986 & 4 & 1686 & 17 & 21 & 0 & 79 \\
\hline$Q \geq 500 \mathrm{t}$ & 11 & 10090 & 5 & 4046 & 40 & 0 & 0 & 100 \\
\hline Total & 600 & 43747 & 24 & 7535 & $17^{\mathrm{a}}$ & & & \\
\hline
\end{tabular}

\footnotetext{
a Percentage of feed consumptions of trout samples in national feed consumptions.
} 

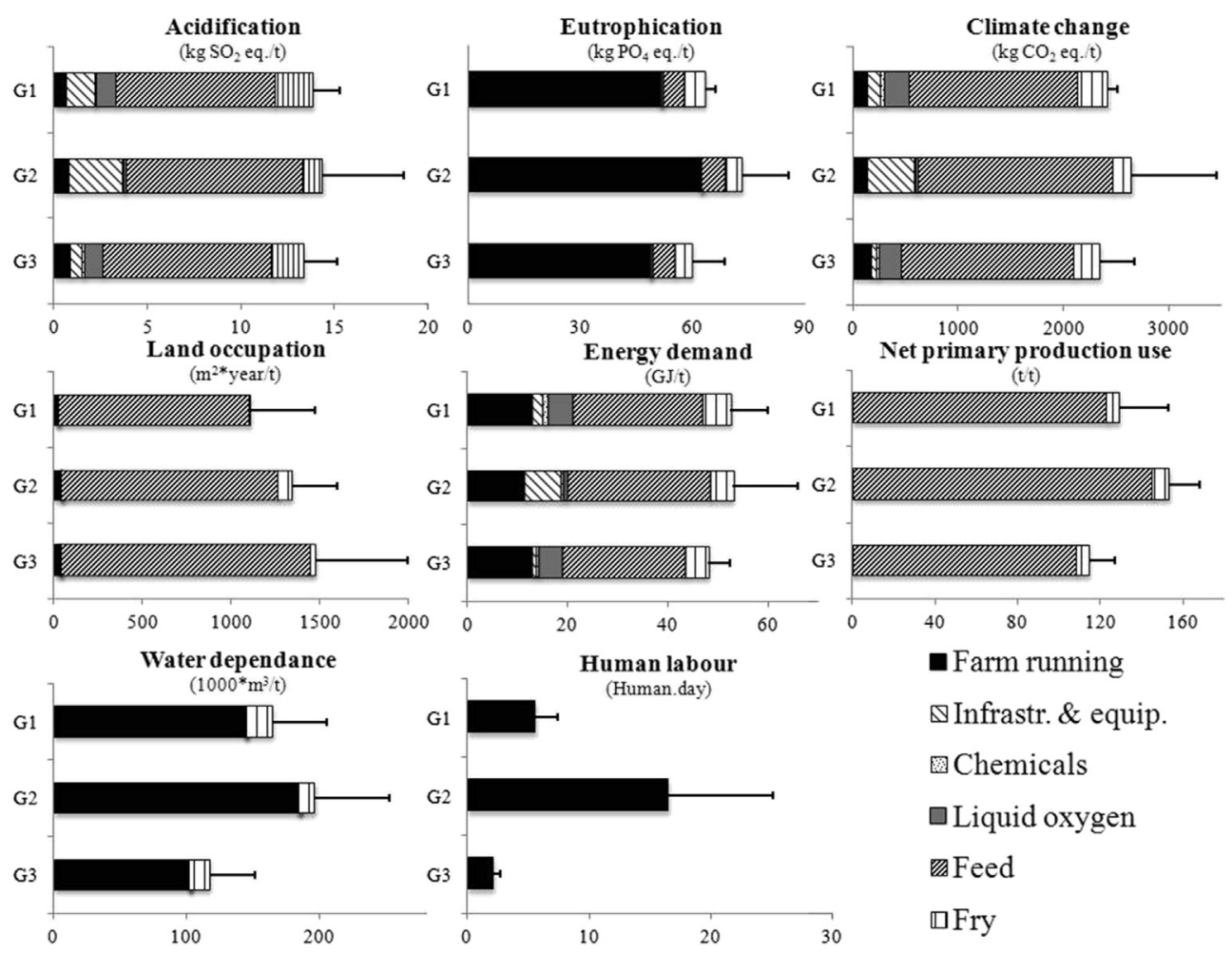

$\otimes$ Infrastr. \& equip.

圈Chemicals

$\square$ Liquid oxygen

Feed

口Fry

Fig. 3. Contribution of system production stages to LCA impacts for trout farms grouped by the size of fish produced: G1 (pan-size), G2 (large and mixed-size) and G3 (very large). Error bars represent $95 \%$ confidence intervals around the means of total impacts.

\section{Discussion}

\subsection{Representativeness of the survey}

Since nearly all farm classes reported in the national inventory are represented in our survey, we consider the representativeness of the survey sufficient, especially for large farms. However, the national inventory did not collect data about the size of trout produced. Even though the results of this study tend to indicate that large and specialized farms have the best performances, it would be interesting to obtain information about the commercial size of trout produced in a larger survey or a future inventory.

\subsection{Comparison of impacts with previous studies}

Comparison of LCA results with those from previous studies is always a delicate question due to methodological differences, especially in definition of system boundaries and allocation of burdens among co-products (Aubin, 2013; Henriksson et al., 2012). Fortunately, most impact categories in LCA studies of salmonid farming are identical and based on the CML2 baseline 2000 v. 2.03 impact assessment method (Guinée et al., 2002). Therefore, one can compare the orders of magnitude of impacts in the same categories for similar types of production.

Mean acidification in our study ranged from 13 to $14 \mathrm{~kg} \mathrm{SO}_{2}$-eq./ $t$, which lies in the same order of magnitude as those in other studies of trout farming: $10.6-16.5 \mathrm{~kg} \mathrm{SO}$-eq./t in Papatryphon et al. (2004b), $19.2 \mathrm{~kg} \mathrm{SO}$-eq./t in Aubin et al. (2009), and $10.8 \mathrm{~kg} \mathrm{SO}$-eq./t in Samuel-Fitwi et al. (2013). Mean eutrophication in our study ranged from 60 to $76 \mathrm{~kg} \mathrm{PO}_{4}$-eq./t, which lies in the same order of magnitude as those of other studies of flow-through trout farms: $74 \mathrm{~kg} \mathrm{PO}$-eq./t in Papatryphon et al. (2004b) and $60 \mathrm{~kg} \mathrm{PO}$-eq./t in Samuel-Fitwi et al. (2013). These eutrophication impacts are higher than those observed in trout reared in recirculating aquaculture systems: $18-21 \mathrm{~kg} \mathrm{PO} 4$-eq./t in Roque d'Orbcastel et al. (2009) and 42-48 kg PO 4 -eq./t in Boissy et al. (2011). Mean climate change in our study (2344-2647 $\mathrm{kg} \mathrm{CO}_{2^{-}}$ eq./t) is similar to that in Samuel-Fitwi et al. (2013), somewhat higher than that in Papatryphon et al. (2004b) (1540-2410 kg CO eq./t), higher than that in Boissy et al. (2011) (2220 kg CO 2 -eq./t), and lower than that in Aubin et al. (2009) (2753 kg CO 2 -eq./t). Mean energy demand in our study $(48-53 \mathrm{GJ} / \mathrm{t})$ is within the range of that in Papatryphon et al. (2004b) (31.0-78.4 GJ/t) and lower than those in Aubin et al. (2009) (78 GJ/t) and Boissy et al. (2011) (55-55.7 GJ/ $\mathrm{t})$. All values of acidification, eutrophication, climate change and energy demand in our study are higher than those in Papatryphon et al. (2004a), whose boundaries encompassed only feed production. NPPU in our study (114-153 t C/t) was at the same level as standard salmon ( $145 \mathrm{t} \mathrm{C/t})$ and trout $(112 \mathrm{t} \mathrm{C} / \mathrm{t})$ in the Boissy et al. (2011) study. The high variation in NPPU found in our study is due to the variability in feed composition and improvements in data on fish meal composition.

\subsection{Farm classification and contribution analysis}

The three groups had similar environmental impacts and were distinguished mainly by technical and economic indicators (e.g., production level, liquid oxygen consumption, NPPU, water dependence, and human labor). G1 farms show intermediate performances. These farms benefit from the biological performances of small trout, combined with more traditional practices than farms from the two other groups. G2 farms show the lowest efficiency of inputs, with high levels of water dependence, NPPU and human labor to produce $1 \mathrm{t}$ of fish. Moreover, this group has less homogeneous characteristics, with higher variability in production level, liquid oxygen consumption and human labor. These 
Table 2

Means of environmental impacts, technical and economic indicators and their coefficients of variation (CV) for trout farms grouped by the size of fish produced: G1 (pan-size), G2 (large and mixed-size), and G3 (very large). Superscript letters indicate significant $(p<0.05)$ differences between groups.

\begin{tabular}{|c|c|c|c|c|c|c|c|}
\hline \multirow[t]{2}{*}{ Indicator } & \multirow[t]{2}{*}{ Unit } & \multicolumn{2}{|l|}{ G1 } & \multicolumn{2}{|l|}{ G2 } & \multicolumn{2}{|l|}{ G3 } \\
\hline & & Mean & $\mathrm{CV}$ & Mean & $\mathrm{CV}$ & Mean & $\mathrm{CV}$ \\
\hline Production level & $\mathrm{t}$ & $168^{a}$ & $56 \%$ & $79^{\mathrm{b}}$ & $94 \%$ & $440^{c}$ & $42 \%$ \\
\hline Feed conversion ratio & & 1.09 & $8 \%$ & 1.17 & $14 \%$ & 1.20 & $18 \%$ \\
\hline Liquid oxygen consumption & $\mathrm{t}$ & $80^{\mathrm{a}}$ & $76 \%$ & $9^{\mathrm{b}}$ & $260 \%$ & $234^{c}$ & $67 \%$ \\
\hline Acidification & $\mathrm{Kg} \mathrm{SO}_{2}$-eq. & 14 & $12 \%$ & 14 & $26 \%$ & 13 & $23 \%$ \\
\hline Eutrophication & $\mathrm{kg} \mathrm{PO}_{4}$-eq. & 63 & $6 \%$ & 73 & $27 \%$ & 60 & $21 \%$ \\
\hline Climate change & $\mathrm{kg} \mathrm{CO}$-eq. & 2425 & $6 \%$ & 2647 & $28 \%$ & 2344 & $20 \%$ \\
\hline Land occupation & $\mathrm{m}^{2 *}$ year & 1099 & $53 \%$ & 1339 & $34 \%$ & 1472 & $56 \%$ \\
\hline Energy demand & GJ & 53 & $15 \%$ & 53 & $29 \%$ & 48 & $18 \%$ \\
\hline Net primary production use & t C & $129^{\mathrm{ab}}$ & $24 \%$ & $153^{a}$ & $20 \%$ & $114^{\mathrm{b}}$ & $15 \%$ \\
\hline Water dependence & $1000 \mathrm{~m}^{3}$ & $164^{\mathrm{ab}}$ & $40 \%$ & $196^{\mathrm{a}}$ & $51 \%$ & $117^{b}$ & $49 \%$ \\
\hline Human labor & human.day & $5.5^{\mathrm{b}}$ & $58 \%$ & $16.5^{\mathrm{a}}$ & $89 \%$ & $2.1^{\mathrm{b}}$ & $60 \%$ \\
\hline
\end{tabular}

Table 3

Matrix of $p$ values of the first three principal components of 11 technical and environmental indicators. Bold values mean variables are significantly $(p<0.05)$ associated with corresponding PC via the bootstrap method.

\begin{tabular}{llll}
\hline Variable & PC1 & PC2 & PC3 \\
\hline Production level & 0.085 & $\mathbf{0 . 0 2 9}$ & 0.150 \\
Feed conversion ratio & 0.096 & 0.482 & $\mathbf{0 . 0 3 2}$ \\
Liquid oxygen consumption & 0.143 & $\mathbf{0 . 0 1 9}$ & 0.147 \\
Acidification & $\mathbf{0 . 0 1 7}$ & 0.165 & 0.305 \\
Eutrophication & $\mathbf{0 . 0 1 1}$ & 0.388 & 0.233 \\
Climate change & $\mathbf{0 . 0 1 5}$ & 0.170 & 0.366 \\
Land occupation & 0.162 & 0.269 & 0.067 \\
Energy demand & $\mathbf{0 . 0 3 4}$ & 0.164 & 0.273 \\
Net primary production use & 0.216 & $\mathbf{0 . 0 3 0}$ & 0.160 \\
Water dependence & 0.117 & 0.135 & 0.364 \\
Human labor & 0.259 & $\mathbf{0 . 0 1 5}$ & 0.271 \\
\hline
\end{tabular}

characteristics reflect the lower level of specialization of the farms through the different markets they supply: small and large trout for food or restocking markets. These more opportunistic and variable strategies lead to lower rearing performances. These strategies can be driven not only by economic considerations, but by choices about quality of life by the farmers. They have the lowest mean production level. In contrast, G3 farms display high efficiency. Their water dependence and NPPU were the lowest of the three groups, and other indicators such as energy use and FCR were not significantly different from the two other groups, although their specialization in producing very large trout induces an increase in the biological FCR and the duration of the production cycle. These farms are the largest of the three groups and they use liquid oxygen to optimize fish performances. These farms aim for maximum efficiency of inputs, including the human labor necessary to produce $1 \mathrm{t}$ of fish, which is the lowest of the three groups. They generally have a high technical level and use genetically improved trout strains.

\subsection{Correlations among variables and bootstrapped PCA results}

The negative correlation between production level and FCR, climate change, energy demand, NPPU, water dependence and human labor indicates that farm production level strongly influenced technical and environmental efficiencies. Economies of scale exist, which lead to an appropriate level of production that balances economic constraints and environmental laws. The significant negative correlation between production and some environmental impacts (e.g., eutrophication, climate change, energy demand, and NPPU) indicates that increasing the size of fish produced tends to reduce these environmental impacts per $t$ of fish. Therefore, an optimal level of production in each group that maximizes production while minimizing environmental impacts could be calculated using optimization modeling. NPPU was positively and significantly correlated with production level and FCR, which shows that the feed system has an important direct influence on trout production but a large indirect influence in regions where feed ingredients are produced. The positive correlations between acidification, eutrophication, climate change and energy demand show that improving the production system could improve all of these impact categories simultaneously.

We used the bootstrapped Kaiser-Guttman criterion (the lower limit of CI for eigenvalues >1) (Guttman, 1954; Lambert et al., 1990) to determine which PCs to retain because this method considers the random sampling error that may influence the distribution of eigenvalues, in which mean value may be below the criterion value (i.e., equals 1 ). In such cases, the bootstrap-based method may be less arbitrary than the traditional Kaiser-Guttman criterion. However, although the bootstrapped Kaiser-Guttman criterion reduces the number of PCs, it may still overestimate that number (Jackson, 1993). Our study shows that projecting the loadings of original variables and individual scores onto two or three PCs more clearly describes correlations among variables and identifies the most influential individuals. However, the explanation based on the observed sample may be less meaningful because its small sample size lacked normality, a prerequisite of PCA. Therefore, the bootstrap-based method shows advantages for interpreting the significance of PCA results. However, more attention should be paid to avoid the re-ordering and reflection problems during the resampling procedure. To overcome these problems, we applied

Table 4

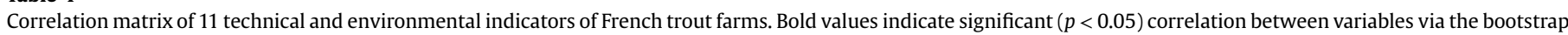
method.

\begin{tabular}{|c|c|c|c|c|c|c|c|c|c|c|c|}
\hline & Prod. & FCR & Oxygen & $A C$ & EU & $\mathrm{CC}$ & Land & Energy & NPPU & Water & Labor \\
\hline Prod. & 1.000 & & & & & & & & & & \\
\hline FCR & -0.044 & 1.000 & & & & & & & & & \\
\hline Oxygen & 0.828 & 0.146 & 1.000 & & & & & & & & \\
\hline$A C$ & -0.378 & 0.235 & -0.125 & 1.000 & & & & & & & \\
\hline EU & -0.416 & 0.455 & -0.255 & 0.706 & 1.000 & & & & & & \\
\hline $\mathrm{CC}$ & -0.362 & 0.231 & -0.134 & 0.934 & 0.758 & 1.000 & & & & & \\
\hline Land & 0.118 & 0.610 & 0.218 & 0.182 & 0.188 & 0.261 & 1.000 & & & & \\
\hline Energy & -0.243 & -0.014 & -0.096 & 0.668 & 0.432 & 0.771 & 0.241 & 1.000 & & & \\
\hline NPPU & -0.410 & 0.405 & -0.355 & -0.180 & 0.169 & -0.041 & 0.184 & -0.027 & 1.000 & & \\
\hline Water & -0.493 & 0.144 & -0.321 & 0.207 & 0.198 & 0.188 & -0.099 & 0.140 & 0.425 & 1.000 & \\
\hline Labor & -0.523 & 0.139 & -0.414 & -0.065 & 0.047 & -0.081 & -0.090 & -0.262 & 0.526 & 0.192 & 1.000 \\
\hline
\end{tabular}

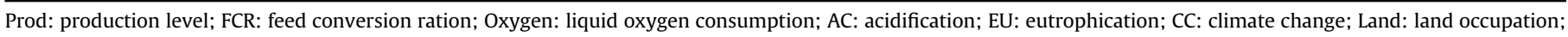
Energy: energy demand; NPPU: Net primary production use; Water: water dependence; Labor: Human labor. 
A:Variable factors map (PC1 vs. PC2)

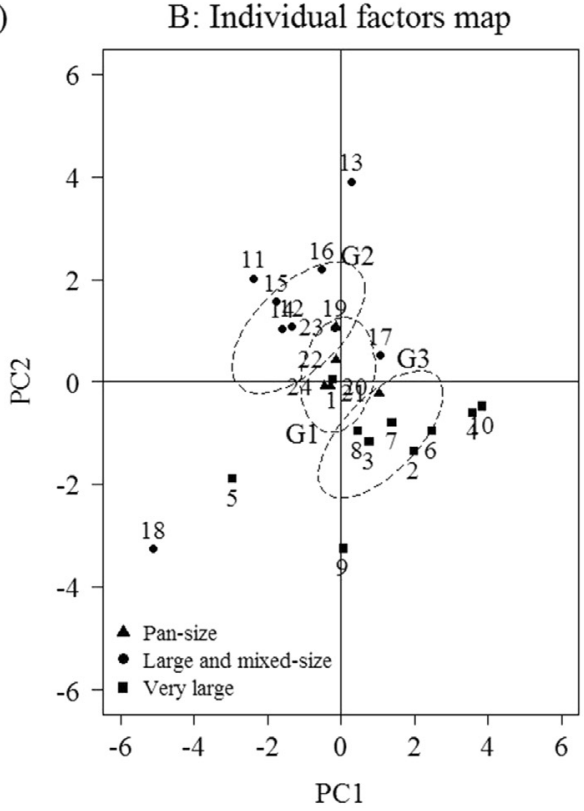

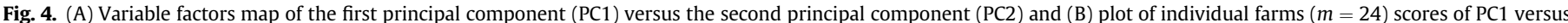

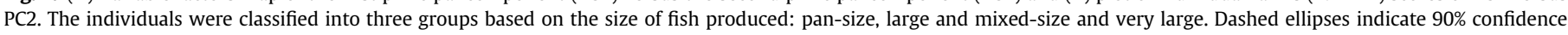
regions of the bootstrapped scores for each group.

the technique proposed by Peres-Neto et al. (2003) in this study, though orthogonal rotation is an equivalent method (Milan and Whittaker, 1995; Timmerman et al., 2007).

\subsection{Bootstrap method}

Most significance tests (e.g., student $t$-test and ANOVA) assume that the population mean is normally distributed, especially when the expected value and variance of the population are known. Although the mean and standard deviation of observed samples are usually used to represent the expected value and the square root of variance of the population, it generally requires a sufficiently large sample size $(n>30)$ or that the parameters of its distribution be known. However, this is not always the case in aquaculture studies (Henriksson et al., 2012; Papatryphon et al., 2004b). Several studies have compared tests of equality to overcome this shortcoming (Boos and Brownie, 2004; Efron and Tibshirani, 1993; Lim and Loh, 1996; Reiczigel et al., 2005). In our study, we used non-parametric bootstrap to perform the significance tests. The $95 \%$ CIs around the differences in group means were used to judge whether or not the null hypothesis was rejected. Bootstrapped results were more conservative and realistic than those from the sample-based calculation because random sampling error was taken into account. Also, the non-normality of some indicators (e.g., production, liquid oxygen consumption, and acidification) suggests that nonparametric bootstrap was more robust than a parametric bootstrap (Potvin and Roff, 1993) because there was no assumption about the true distribution of indicators to represent the whole population. Another advantage of the bootstrap method is its ability to estimate CIs around some statistics which cannot be obtained from the observed sample. In this study, for example, BCa was used to estimate CIs for the correlations, which were used to validate their significance. As concluded by Mudelsee (2003), nonparametric bootstrap was a robust method for estimating CIs for Pearson's correlation coefficients.

As an approximation method, however, the bootstrap method is designed to estimate uncertainty in any statistical value (e.g., mean, median and correlation coefficient), and the accuracy of bootstrapped results depends on the quality and quantity of the observed sample (Luo et al., 2013; Wisz et al., 2008). Nevertheless, when parametric assumption is justified (satisfying normality and homogeneity of variance), Efron (1988) suggested using parametric bootstrap, which is more accurate than non-parametric bootstrap. To do so, more data are required to increase the reliability of parametric bootstrap. In addition, the quality of secondary data used in an analysis may result in additional uncertainty (e.g., inaccurate measurement and unrepresentative data). Thus, increasing data quality could reduce parameter uncertainty and provide more accurate results (Henriksson et al., 2013; Weidema and Wesnaes, 1996).

\section{Conclusion}

In this study, a small sample of survey data was used to compare three types of trout production systems. The results showed strong links between technical/economic and environmental indicators. Non-parametric bootstrap and BCa-based CIs were applied to better estimate uncertainty in the statistical values. PCA showed the relative influences of variable indicators and individual scores. Technical/economic indicators (production level, human labor) were the main drivers and were correlated with environmental impacts such as eutrophication and climate change. So, improving rearing performances is one way to decrease environmental impacts. The remaining variability in indicators within farm groups showed that there is room to improve farm management and decrease environmental impacts, especially in G2, whose less specialized production led to less control over management parameters. Feed and liquid oxygen consumption are the main factors that influence the environmental impacts. Furthermore, these indicators reflect practices such as the monitoring of fish growth, water quality, and feeding practices. The three groups had few differences in environmental impacts. Despite the small sample size, our bootstrapped PCA method reinforces this overall conclusion. 
Consideration of uncertainty in LCA is an improvement that is frequently cited. We applied a method to address the uncertainty due to a small sample size in an LCA-based case study. For the first time, non-parametric bootstrapped PCA has been used to assess groups of trout farms, and it is able to express uncertainty in statistical parameters of indicators. In the future, to provide reliable results, data quality and other types of uncertainty should be considered throughout the entire system.

\section{Acknowledgements}

The authors thank Michael Corson for reviewing earlier versions of this manuscript and helping improve its English content.

\section{Appendix. Bias-corrected and accelerated (BCa) bootstrap method}

The BCa method is used to estimate the confidence interval of a statistic of interest $\theta$ (e.g., mean and median) at significance level $\alpha$ (Efron and Tibshirani, 1993). Its lower and upper limits are found at the $100 \alpha_{1}$ th and $100 \alpha_{2}$ th percentile of bootstrap distribution, respectively:

$\alpha_{1}=\Phi\left(z_{0}+\frac{z_{0}+z^{\alpha}}{1-a\left(z_{0}+z^{\alpha}\right)}\right)$

$\alpha_{2}=\Phi\left(z_{0}+\frac{z_{0}+z^{(1-\alpha)}}{1-a\left(z_{0}+z^{(1-\alpha)}\right)}\right)$

where $\Phi$ is the standard normal cumulative distribution function, $z^{\alpha}$ is the $100 \alpha$ th percentile point of $\Phi$, and $z_{0}$ is calculated as:

$z_{0}=\Phi^{-1}\left(\frac{\theta_{i}^{*}<\theta}{B}\right)$

where $\Phi^{-1}$ is the inverse of the standard normal cumulative distribution function, $\theta_{i}^{*}$ is the $i$ th bootstrap estimate of $\theta$, and $\mathrm{B}$ is the number of the iteration.

Skewness is corrected by the "accelerated indicator" $a$, which is calculated as:

$a=\frac{\sum_{n=1}\left(\theta^{\prime}-\theta_{n}\right)^{3}}{6^{*}\left(\sum_{n=1}\left(\theta^{\prime}-\theta_{n}\right)^{2}\right)^{3 / 2}}$

where $\theta_{n}$ is the estimated statistic of interest from the observed sample without the $n$th row (jackknife replicate) and $\theta^{\prime}$ is the mean of $\theta_{n}$.

\section{References}

Agreste, 2009. Recensements de la salmoniculture. Agreste.

Agreste, 2011. La salmoniculture, un secteur en recul (première partie). Agreste, les dossiers 11. Ministère de l'Agriculture, de l'agroalimentaire et de la forêt, pp. 7-60.

Aubin, J., 2013. Life cycle assessment as applied to environmental choices regarding farmed or wild-caught fish. CAB Rev, 8, 1-10.

Aubin, J., Papatryphon, E., van der Werf, H.M.G., Chatzifotis, S., 2009. Assessment of the environmental impact of carnivorous finfish production systems using life cycle assessment. J. Clean. Prod. 17, 354-361.

Aubin, J., Tocqueville, A., Kaushik, S.J., 2011. Characterisation of waste output from flow-through trout farms in France: comparison of nutrient mass-balance modelling and hydrological methods. Aquat. Living Resour. 24, 63-70.

Ayer, N.W., Tyedmers, P.H., 2009. Assessing alternative aquaculture technologies: life cycle assessment of salmonid culture systems in Canada. J. Clean. Prod. 17, $362-373$.
Babamoradi, H., van den Berg, F., Rinnan, A., 2013. Bootstrap based confidence limits in principal component analysis - a case study. Chemom. Intell. Lab. 120, 97-105.

Berthouex, P.M., Brown, L.C., 2002. Statistics for Environmental Engineers, second ed. CRC Press LLC, USA.

Boissy, J., Aubin, J., Drissi, A., van der Werf, H.M., Bell, G.J., Kaushik, S.J., 2011 Environmental impacts of plant-based salmonid diets at feed and farm scales. Aquaculture 321, 61-70.

Boos, D.D., Brownie, C., 2004. Comparing variances and other measures of dispersion. Stat. Sci. 19, 571-578.

Cao, L., Diana, J.S., Keoleian, G.A., 2013. Role of life cycle assessment in sustainable aquaculture. Rev. Aquacult. 5, 61-71.

d'Orbcastel, E.R., Blancheton, J.-P., Aubin, J., 2009. Towards environmentally sustainable aquaculture: comparison between two trout farming systems using life cycle assessment. Aquacult. Eng. 40, 113-119.

Daudin, J., Duby, C., Trecourt, P., 1988. Stability of principal component analysis studied by the bootstrap method. Statistics 19, 241-258.

Dehlholm, C., Brockhoff, P.B., Bredie, W.L., 2012. Confidence ellipses: a variation based on parametric bootstrapping applicable on multiple factor analysis results for rapid graphical evaluation. Food. Qual. Prefer 26, 278-280.

Efron, B., 1979. Bootstrap methods - another look at the jackknife. Ann. Stat. 7 $1-26$.

Efron, B., 1988. Bootstrap confidence interval - good or bad. Psychol. Bull. 104, 293-296.

Efron, B., Tibshirani, R., 1993. An Introduction to the Bootstrap. CRC press.

European Commision, 2010. International Reference Life Cycle Data System (ILCD) Handbook -General Guide for Life Cycle Assessment. Joint Research Centre - Institute for Environment and Sustainability, Office of the European Union, Luxembourg.

FAO, 2012. The State of World Fisheries and Aquaculture 2012. Fisheries and Aquaculture Department, Food and Agriculture Organization of the United Nations, Rome.

Frischknecht, R., Jungbluth, N., Althaus, H.J., Doka, G., Dones, R., Heck, T. Hellweg, S., Hischier, R., Nemecek, T., Rebitzer, G., 2005. The ecoinvent database: overview and methodological framework. Int. J. Life. Cycle Assess. 10, $3-9$.

Gronroos, J., Seppala, J., Silvenius, F., Makinen, T., 2006. Life cycle assessment of Finnish cultivated rainbow trout. Boreal Environ. Res. 11, 401.

Guinée, J., Gorree, M., Heijungs, R., Huppes, G., Kleijn, R., 2002. Handbook on Life Cycle Assessment: Operational Guide to the ISO Standards. Kluwar Academic Dordrecht, Netherlands.

Guttman, L., 1954. Some necessary conditions for common-factor analysis. Psychometrika 19, 149-161.

Henriksson, P.J., Guinée, J.B., Heijungs, R., de Koning, A., Green, D.M., 2013. A protocol for horizontal averaging of unit process data - including estimates for uncertainty. Int. J. Life Cycle. Assess. 19, 1-8.

Henriksson, P.J., Guinée, J.B., Kleijn, R., de Snoo, G.R., 2012. Life cycle assessment of aquaculture systems - a review of methodologies. Int. J. Life Cycle. Assess. 17, 304-313.

ISO 14040, 2006. Environmental Management - Life Cycle Assessment - Principles and Framework (ISO 14040:2006). International Organization for Standardization, Geneva.

ISO 14044, 2006. Environmental Management - Life Cycle Assessment - Requirements and Guidelines (ISO 14044:2006). International Organization for Standardization, Geneva.

Jackson, D., 1993. Stopping rules in principal components analysis: a comparison of heuristical and statistical approaches. Ecology 2204-2214.

Jackson, D., 1995. Bootstrapping principal components analysis - reply to Mehlman et al. Ecology 76, 644-645.

Jolliffe, I., 2005. Principal Component Analysis, second ed. Wiley Online Library.

Lambert, Z.V., Wildt, A.R., Durand, R.M., 1990. Assessing sampling variation relative to number-of-factors criteria. Educ. Pyschol. Meas. 50, 33-48.

Lazard, J., Baruthio, A., Mathé, S., Rey-Valette, H., Chia, E., Clément, O., Aubin, J., Morissens, P., Mikolasek, O., Legendre, M., 2010. Aquaculture system diversity and sustainable development: fish farms and their representation. Aquat. Living Resour. 23, 187-198.

Lim, T.-S., Loh, W.-Y., 1996. A comparison of tests of equality of variances. Comput. Stat. Data Anal. 22, 287-301.

Luo, Z., Atamturktur, S., Juang, C.H., 2013. Bootstrapping for characterizing the effect of uncertainty in sample statistics for braced excavations. J. Geotech. Geoenviron. 139, 13-23.

Mehlman, D.W., Shepherd, U.L., Kelt, D.A., 1995. Bootstrapping pricipal components analysis - a comment. Ecology 76, 640-643.

Melia, P., Petrillo, M., Albertelli, G., Mandich, A., Gatto, M., 2012. A bootstrap approach to account for uncertainty in egg production methods applied to small fish stocks. Fish. Res. 117, 130-136.

Milan, L., Whittaker, J., 1995. Application of the parametric bootstrap to models that incorporate a singular value decomposition. Appl. Stat. 44, 31-49.

Mudelsee, M., 2003. Estimating Pearson's correlation coefficient with bootstrap confidence interval from serially dependent time series. Math. Geol. 35, $651-665$.

Papatryphon, E., Petit, J., Kaushik, S.J., van der Werf, H.M., 2004a. Environmenta impact assessment of salmonid feeds using life cycle assessment (LCA). Ambio 33, 316-323.

Papatryphon, E., Petit, J., Van der Werf, H., Kaushik, S., Saint-Pée-sur-Nivelle, F. 2004b. Life cycle assessment of trout farming in France: a farm level approach. 
In: Life Cycle Assessment in the Agri-food Sector. DIAS Report 61. Presented at the 4th International Conference, pp. 71-76.

Papatryphon, E., Petit, J., Van Der Werf, H.M., Sadasivam, K.J., Claver, K., 2005. Nutrient-balance modeling as a tool for environmental management in aquaculture: the case of trout farming in France. Environ. Manage. 35, 161-174.

Pelletier, N., Tyedmers, P., 2007. Feeding farmed salmon: is organic better? Aquaculture 272, 399-416.

Pelletier, N., Tyedmers, P., Sonesson, U., Scholz, A., Ziegler, F., Flysjo, A., Kruse, S. Cancino, B., Silverman, H., 2009. Not all salmon are created equal: life cycle assessment (LCA) of global salmon farming systems. Environ. Sci. Technol. 43, 8730-8736.

Peres-Neto, P.R., Jackson, D.A., Somers, K.M., 2003. Giving meaningful interpretation to ordination axes: assessing loading significance in principal component analysis. Ecology 84, 2347-2363.

Potvin, C., Roff, D.A., 1993. Distribution-free and robust statistical methods: viable alternatives to parametric statistics. Ecology 1617-1628.
R Development Core Team, 2012. R: a Language and Environment for Statistical Computing. R Foundation for Statistical Computing, Vienna, Austria. Retrieved from http://www.R-project.org.

Reiczigel, J., Zakarias, D., Rozsa, L., 2005. A bootstrap test of stochastic equality of two populations. Am. Stat. 59, 156-161.

Samuel-Fitwi, B., Nagel, F., Meyer, S., Schroeder, J.P., Schulz, C., 2013. Comparative life cycle assessment (LCA) of raising rainbow trout (Oncorhynchus mykiss) in different production systems. Aquacult. Eng. 54, 85-92.

Timmerman, M.E., Kiers, H.A., Smilde, A.K., 2007. Estimating confidence intervals for principal component loadings: a comparison between the bootstrap and asymptotic results. Br. J. Math. Stat. Psychol. 60, 295-314.

Weidema, B., Wesnaes, M.S., 1996. Data quality management for life cycle inventoriesan example of using data quality indicators. J. Clean. Prod. 4, 167-174.

Wisz, M.S., Hijmans, R., Li, J., Peterson, A.T., Graham, C., Guisan, A., 2008. Effects of sample size on the performance of species distribution models. Divers. Distrib. $14,763-773$. 